\title{
EFFECT OF VENEER COMPOSITION ON THE STIFFNESS AND STRESS OF LAMINATED WOOD
}

\author{
Seid Hajdarevic, Murco Obucina \& Elmedin Mesic
}
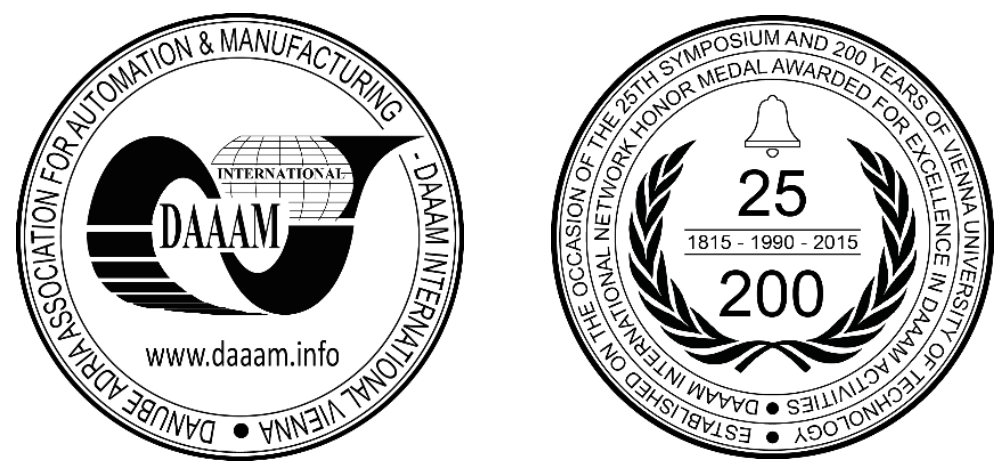

This Publication has to be referred as: Hajdarevic, S[eid]; Obucina, M[urco] \& Mesic, E[lmedin] (2017). Effect of Veneer Composition on the Stiffness and Stress of Laminated Wood, Proceedings of the 28th DAAAM International Symposium, pp.0341-0350, B. Katalinic (Ed.), Published by DAAAM International, ISBN 978-3-902734-11-2, ISSN 1726-9679, Vienna, Austria

DOI: $10.2507 / 28$ th.daaam.proceedings.047

\begin{abstract}
The stiffness and stress analysis of beech wood laminated straight and curved cantilever beam is performed in the paper. Analysis was conducted layer by layer on the laminated beams with different veneer compositions. Finite element analysis is carried out with a '2D linear elastic model' for orthotropic materials. Analytic stiffness and stress evaluation is carried out by a 'transformed cross section method'. The influence of the veneer fiber orientation, veneer position, and thickness on the mechanical properties of laminated wood and the possibilities of both used methods for design of different shape of laminated wood have been analyzed. The results revealed that the laminated wood beam is stiffer when the outside veneers have longitudinal orientation in span direction or the thickness of outside veneers with longitudinal orientation is greater and that longitudinally oriented veneers sustain larger stress than veneers with tangential orientation. The results obtained by both used methods confirm that it can be used to achieve behaviour analysis of laminated wood in rectangular form. Curved forms require more complex analysis, but the methods can be used to achieve approximate data. The numerical in-plane stress analysis that applied to curved beam is not capable to calculating radial (interlaminar) stress.
\end{abstract}

Keywords: laminated wood; veneer composition; stiffness; stress; FEM; transformed cross section method

\section{Introduction}

Laminated wood composites have wide range of application in furniture industry due to their specific mechanical and physical properties. Today, plywood and curved veneer products e.g. plywood shell are the basic elements of a certain type of furniture constructions and there is considerable interest in the development of new complex forms. A better understanding of effect of veneer parameters on mechanical properties of laminated element can lead to improvement of quality of the laminated wood products.

Basic concepts of laminated wood analysis are introduced by analyzing a symmetric three-layer orthotropic laminate for the plane stress condition. Analysis of laminates is based on knowledge of the elastic parameters of individual laminae and component organization [1]. More extended analytic model can be finds in reference [2]. The model allows determining the stress condition of curved beam due bending. Numerical methods, such as the 'finite element method', 
are applicable and effective for the analysis of laminated wood. The limitations of numerical analysis depend on the complexity of numerical models and it is related to the simplifying assumptions that are introduced [3].

Plywood and curved veneer products are a balanced construction made of veneer sheets. The properties of the laminated product depend on parameters of production process and properties of individual veneers. Authors are focused on the determination of stresses and deformations develop during the manufacture veneer products [4], the analysis of shape stability with different fiber orientations and moisture content variations [5] and the impact of veneer layouts on strength of laminated wood [6]. Veneer properties are considered as design tool which has effect on the behavior of laminated wood structure $[7,8]$.

\section{Research objective and methodology}

The aim of this study was to determine stiffness and stress of the laminated wood structure, calculated by different methods and to compare the results in order to determine the effects of method, assumptions and simplifications used in the calculation of a structure's stiffness and stress. The objective was to make transparent what results are to be expected, depending on what approach to structural design was taken.

This study employed a numerical method (FEM) and the transformed cross section method for the analysis of the stiffness and normal stress of the straight and curved cantilever beams. The effects of the veneer composition on the behavior of laminate wood beams used in this study were determined in order to describe the influence of the veneer fiber orientation, veneer position, and thickness on the stiffness and stress distribution of laminated wood constructions.

\subsection{Mathematical model}

The equation of momentum balance, expressed in the Cartesian tensor notation [9]

$$
\int_{S} \sigma_{i j} n_{j} d S+\int_{V} f_{i} d V=0
$$

and of the constitutive relation for the elastic material

$$
\sigma_{i j}=C_{i j k l} \varepsilon_{k l}=\frac{1}{2} C_{i j k l}\left(\frac{\partial u_{k}}{\partial x_{l}}+\frac{\partial u_{l}}{\partial x_{k}}\right)
$$

describe the stress and strain of a loaded solid body in static equilibrium. In the equations above, $\mathrm{x}_{\mathrm{j}}$ are Cartesian spatial coordinates, $V$ is the volume of solution domain bounded by the surface $S, \sigma_{\mathrm{ij}}$ is the stress tensor, $n_{j}$ is the outward unit normal to the surface $S, f_{\mathrm{i}}$ is the volume force, $C_{i j k l}$ is the elastic constant tensor components, $\varepsilon_{k l}$ is the strain tensor, and $u_{k}$ represents the point displacement. Twelve non-zero orthotropic elastic constants $A_{i j}$ are related to the Young's modulus $E_{i}$, the Poisson's ratio $v_{i j}$, and the shear modulus $G_{i j}$.

In order to complete the mathematical model, the boundary conditions have to be specified. The surface $\operatorname{traction} f_{S i}$ and/or the displacement $u_{S}$ at the domain boundaries are known, i.e.

$$
\sigma_{i j} n_{j}=f_{S_{i}} \text { and } u_{i}=u_{S}
$$

Governing equations (1) combined with the constitutive relations (2) are solved a numerical method based on the finite element as a 2D problem with shell elements. Each layer is defined by a unique set of material properties and orientation. Calculations were performed by using the Catia software package.

\subsection{Analytic evaluation - Transformed cross section method}

Equations for analytic evaluation of a multilayer symmetric laminate subjected to bending are obtained by the method of transformed cross section. This method permits the conversion of the moduli of the various laminate to a single modulus of the beam and has the effect of reducing or increasing the width of laminae in relation to the reference width of the selected lamina [1]. The equation for transfer of width, Fig. 1, is:

$$
b^{i}=b\left(\frac{E_{z}^{i}}{E_{z}^{n}}\right)
$$


where: $b$ - width of the face, reference lamina, $E_{z}$ - modulus of elasticity in the direction of span (in the $z$ direction). The general equation for the moment of inertia $I_{x}^{\prime}$ of the transformed cross section is:

$$
I_{x}^{\prime}=\frac{2 b}{E_{z}^{n}} \sum_{i=1}^{n}\left[\frac{E_{z}^{i}\left(d^{i}\right)^{3}}{12}+E_{z}^{i} d^{i}\left(\sum_{1}^{i-1} d^{i-1}+\frac{d^{i}}{2}\right)^{2}\right]
$$

where: $d$ - thickness of lamina.

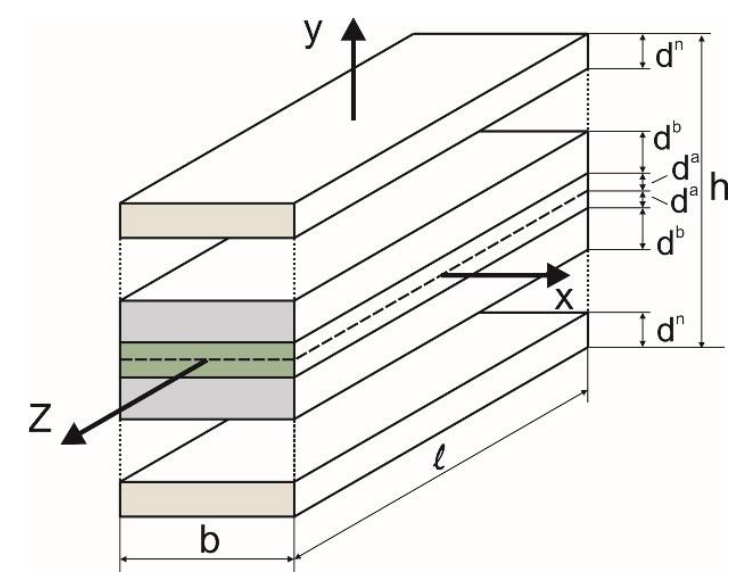

a)

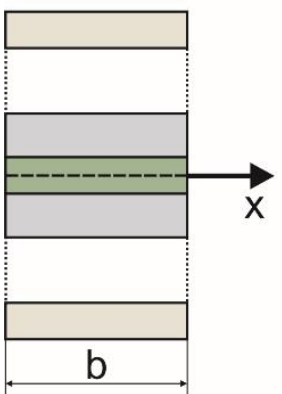

Fig. 1. a) symmetric multilayer orthotropic laminate, b) geometry and transformed cross section

\subsection{Physical model}

Two examples of laminated wood beam were analysed, Fig 2. The straight and curved beams are supported as a cantilever and are loaded at its end by a force of $10 \mathrm{~N}$. Dimensions of rectangular beams cross-section are $\boldsymbol{b}=\mathbf{2 0} \mathrm{mm}$ and $\boldsymbol{h}=\mathbf{8} \mathrm{mm}$. Length of the straight beams is $\boldsymbol{l}_{\mathbf{1}}=\mathbf{2 0 0} \mathrm{mm}$ and lengths of the curved beam straight sections are $\boldsymbol{l}_{\mathbf{2}}=$ $\mathbf{5 0} \mathbf{~ m m}$. The radius of centroidal axis of the curved cantilever beam is $\boldsymbol{R}=\mathbf{1 0 0} \mathbf{m m}$. The objective was to determine the vertical deflection at free end and the normal stress $\sigma_{z}$ of the both beams.

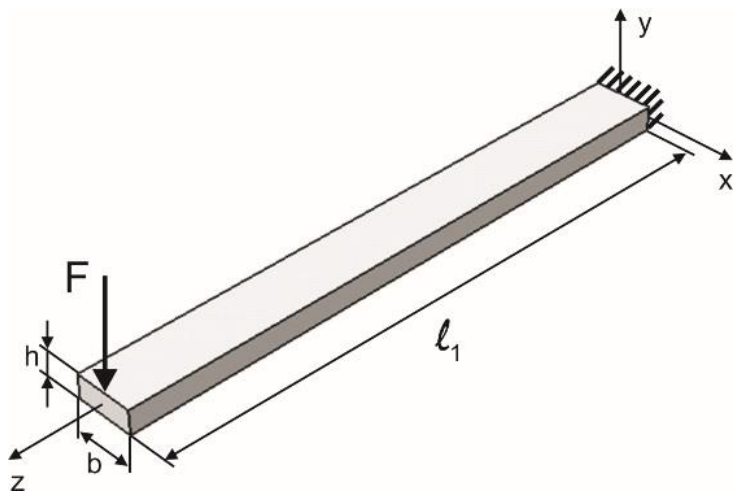

a)

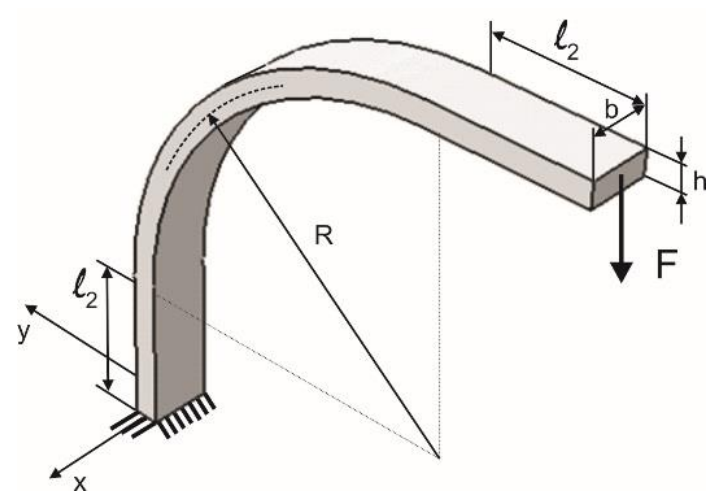

b)

Fig. 2. Static scheme and dimensions: a) cantilever beam, b) curved cantilever beam

Calculation was carried out for beech wood (Fagus silvatica L.). Its elastic properties for wood density $\rho=0,75 \mathrm{~g} / \mathrm{cm}^{3}$ are presented in Tab. 1 [10]. Appropriate elastic properties for analysis in the LT plane were selected.

\begin{tabular}{|c|c|c|c|c|c|c|c|c|c|c|c|}
\hline \multicolumn{3}{|c|}{ Modulus of elasticity, GPa } & \multicolumn{1}{|c|}{ Rigidity modulus, GPa } & \multicolumn{6}{c|}{ Poisson's ratio } \\
\hline$E_{L}$ & $E_{R}$ & $E_{T}$ & $G_{L R}$ & $G_{L T}$ & $G_{R T}$ & $v_{L R}$ & $v_{L T}$ & $v_{R T}$ & $v_{T R}$ & $v_{R L}$ & $v_{T L}$ \\
\hline 13,969 & 2,284 & 1,160 & 1,645 & 1,082 & 0,471 & 0,450 & 0,510 & 0,750 & 0,360 & 0,075 & 0,044 \\
\hline
\end{tabular}

Table 1. Elastic properties of beech (Fagus silvatica L.) [10] 
Investigations were conducted on the laminated beams with six different veneer compositions. Orientation and thickness of veneers are shown in Fig. 3. Compositions are symmetric and consist of an even number of veneer.
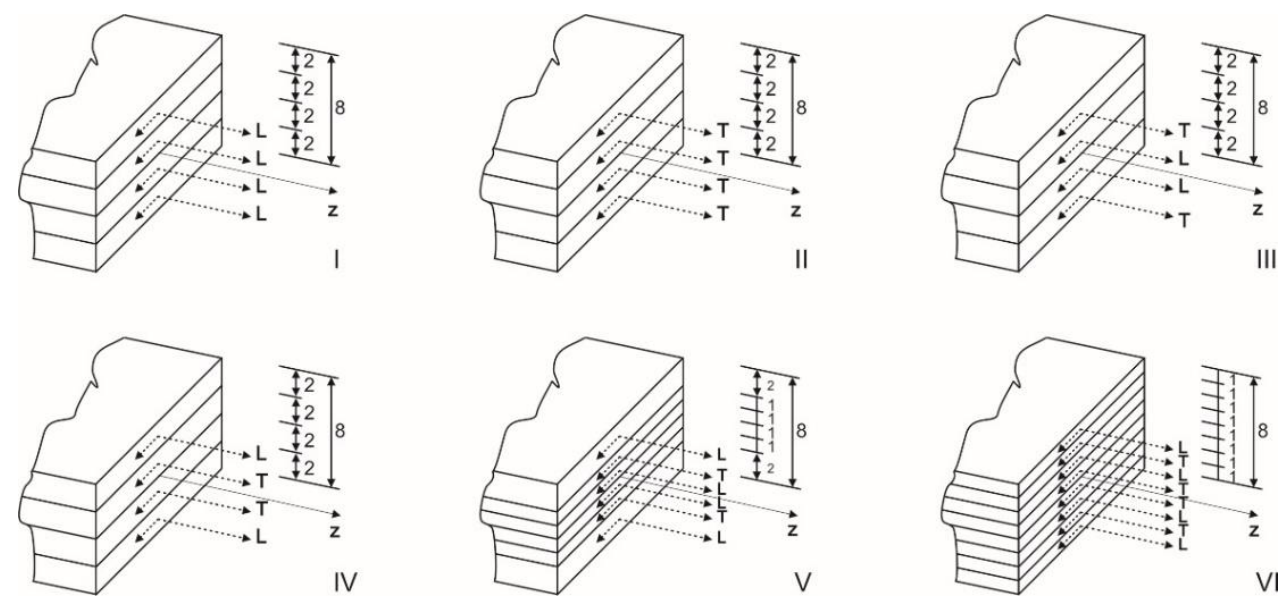

Fig. 3. Six different veneer compositions - orientation and thickness of veneers

\section{Results}

The results of the numerical calculation comprising vertical translation displacement magnitude of the straight cantilever beam and the curved cantilever beam are shown in Fig. 4 and Fig. 5.

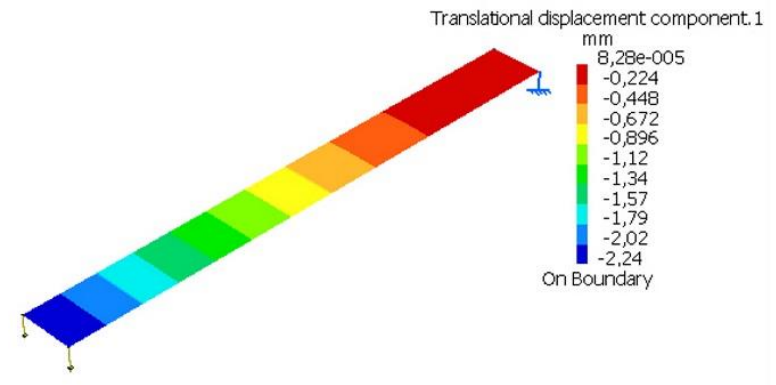

I

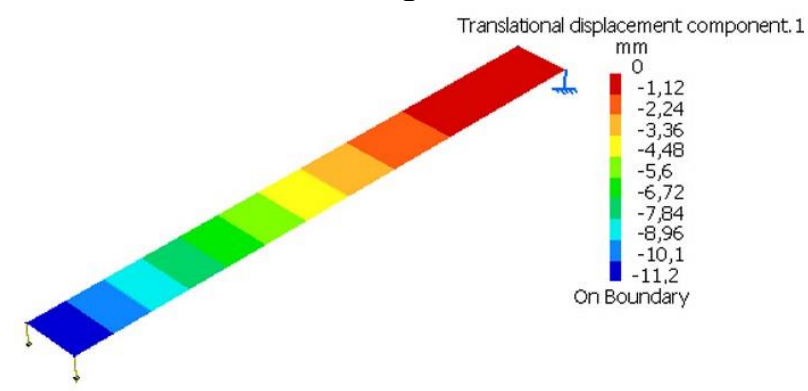

III

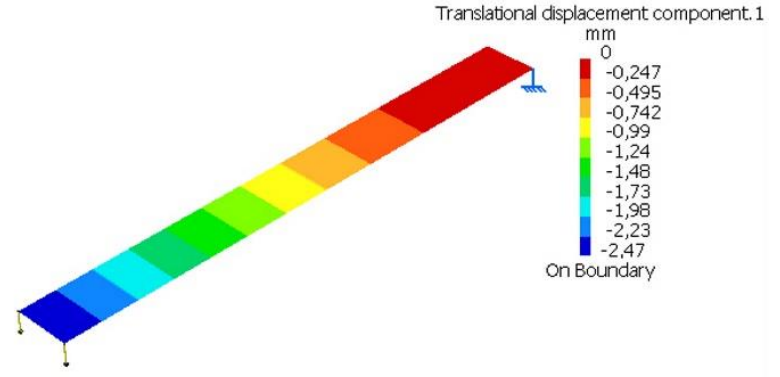

$\mathrm{V}$

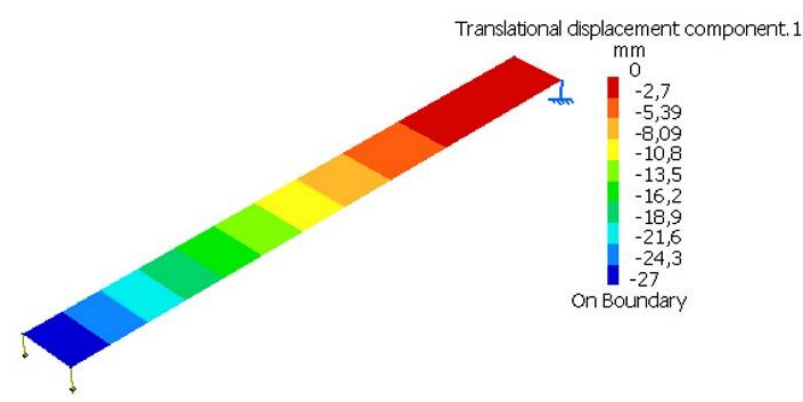

II

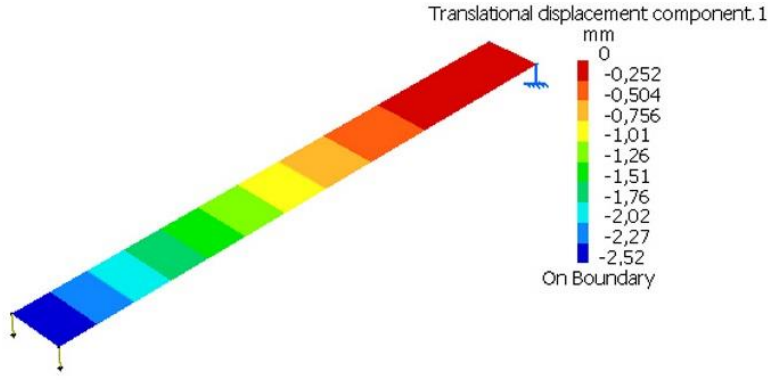

IV

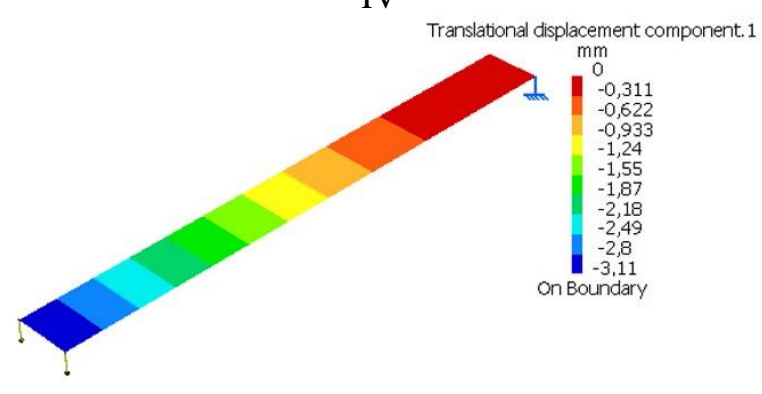

VI

Fig. 4. Deflection straight cantilever beam for six veneer compositions 
As was expected, the stiffness analysis revealed that the extreme values of displacement occur in cases of veneer composition with identical orientation of all veneers in span direction (case I and II). Effects of the elastic parameters and position of the individual veneer on the beam stiffness are evident in case III and IV. The outside veneers contribute more toward the bending stiffness than those close to the neutral plane. Beam stiffness is not significantly improved by placing veneers with longitudinally orientation in span direction near the neutral line (case V). By placing veneers with tangential orientation in span direction near the outside of a beam (case VI), beam stiffness is significantly decreased. The results of analysis of the curved beam displacement are shown identical effect of the veneer composition on the beam stiffness.

IV
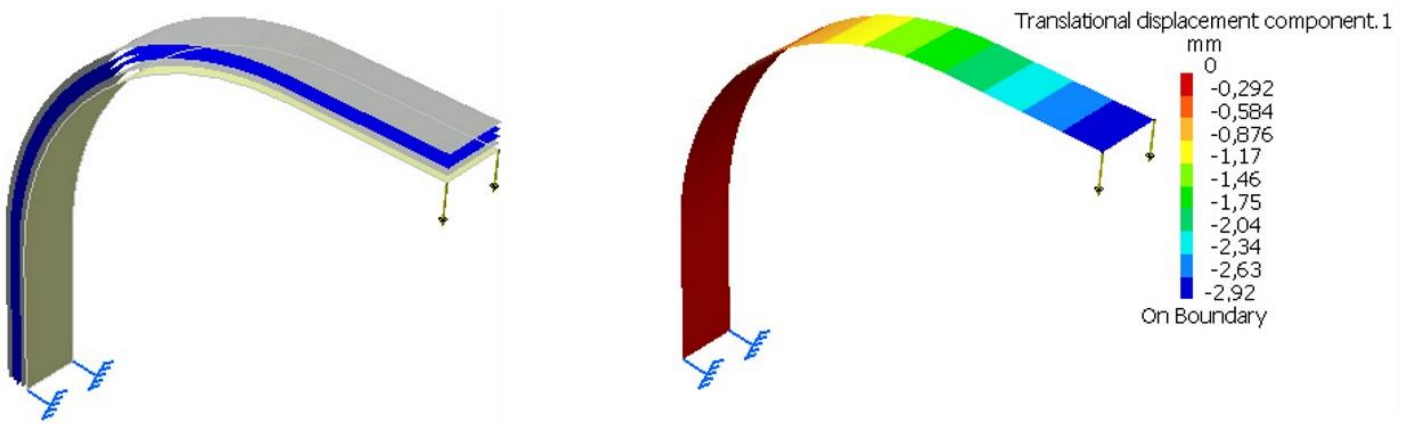

V
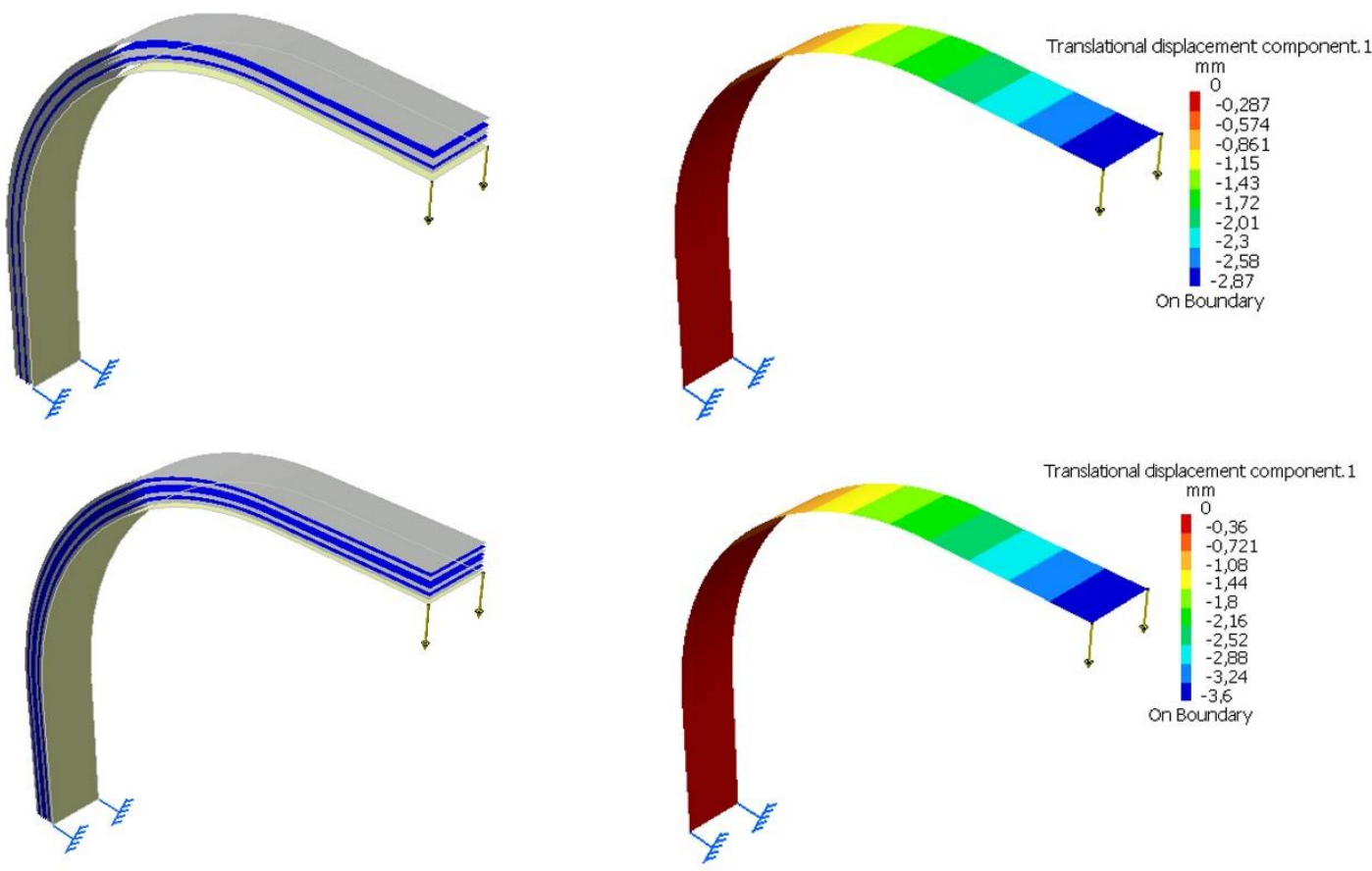

Fig. 5. Deflection of curved cantilever beam for three veneer compositions

Analitical results of the loaded end deflection of the straight cantilever beam are obtained from:

$$
f_{y}=\frac{c F l_{1}^{3}}{E_{z}^{n} I_{x}^{\prime}}
$$

where: $F$ - concentrated load, $c=1 / 3$ - the constant depends of the loading condition and $l_{1}$ - beam length. Vertical displacements of the curved cantilever beam at the loaded end are obtained using Castigliano's theorem. The strain energy due to axial and shear force are neglected and the strain energy due to bending moment in the curved section of the beam is approximated as:

$$
W=\frac{1}{2} \int \frac{M_{x}^{2} R}{E_{z}^{n} I_{x}^{\prime}} d \theta \text { for } \frac{R}{h}>10
$$

where: $R$ - radius of curvature measured to centroid of section and $h$ - heigth of curved beam. The deflection of the curved beam in the direction of the force is found as: 
$\delta=\frac{F}{E_{Z}^{n} l_{x}}\left(\frac{4}{3} l_{2}^{3}+l_{2}^{2} R \frac{(\pi+4)}{2}+3 l_{2} R^{2}+\frac{\pi}{4} R^{3}\right)$.

The analytical and numerical results comprising vertical displacement for six veneer compositions of the straight cantilever beam and for three veneer compositions of the curved cantilever beam are given in Tab. 2. Differences between displacement obtained by analytical and numerical calculation are $<1 \%$ for straight beam and $8.6 \%$ for curved beam.

\begin{tabular}{|c|c|c|r|r|}
\hline \multirow{2}{*}{$\begin{array}{c}\text { Beam cross section } \\
\text { bxh=20x8 } \mathrm{mm}^{2}\end{array}$} & \multirow{2}{*}{ Veneer composition } & \multicolumn{2}{|c|}{ Analytical result } & Numerical result \\
\cline { 3 - 5 } & & $\begin{array}{c}\text { Moment of inertia } \\
I_{x}^{\prime}, \mathrm{m}^{4}\end{array}$ & Displacement, mm & Displacement, mm \\
\hline \multirow{4}{*}{ Straight cantilever beam } & I & $8,533 \cdot 10^{-10}$ & 2,237 & 2,24 \\
\cline { 2 - 5 } & II & $8,533 \cdot 10^{-10}$ & 26,93 & 27,0 \\
\cline { 2 - 5 } & III & $2,031 \cdot 10^{-9}$ & 11,31 & 2,2 \\
\cline { 2 - 5 } & IV & $7,544 \cdot 10^{-10}$ & 2,530 & 2,52 \\
\cline { 2 - 5 } & V & $7,679 \cdot 10^{-10}$ & 2,485 & 3,11 \\
\hline \multirow{3}{*}{ Curved cantilever beam } & VI & $6,117 \cdot 10^{-10}$ & 3,120 & 2,92 \\
\cline { 2 - 5 } & IV & $7,544 \cdot 10^{-10}$ & 3,173 & 2,87 \\
\cline { 2 - 5 } & V & $7,679 \cdot 10^{-10}$ & 3,117 & 3,60 \\
\hline
\end{tabular}

Table 2. Vertical displacements of straight and curved cantilever beams

The results of the numerical calculation comprising the normal stress $\sigma_{z}$ in the individual layers of the straight cantilever beam are shown in Fig. 6.

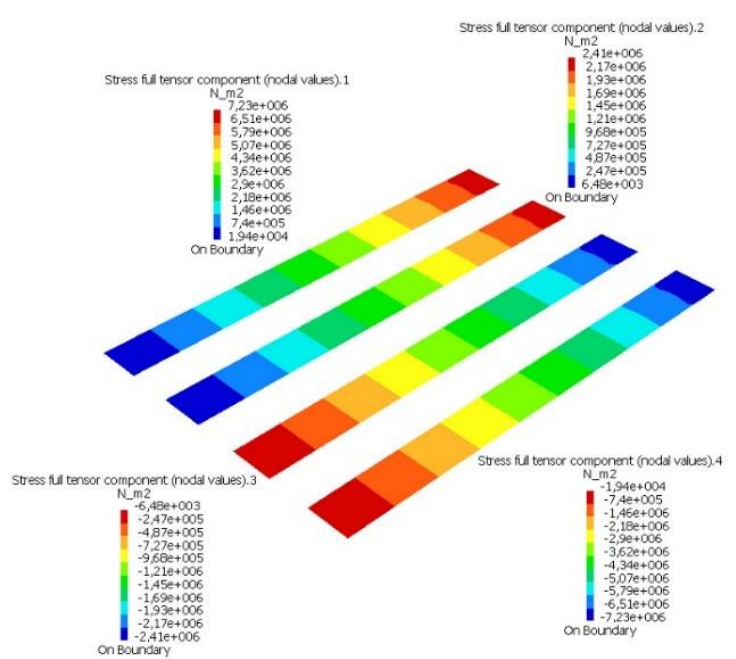

I

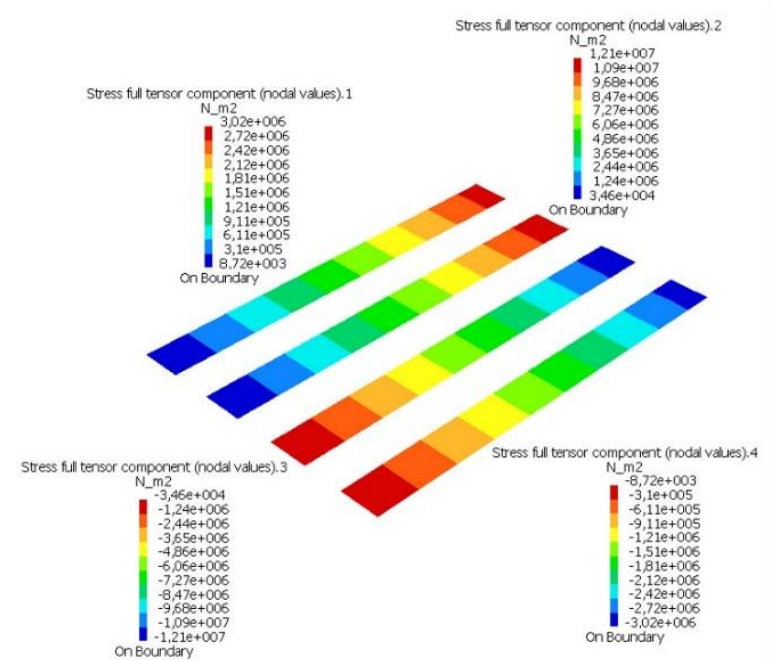

III

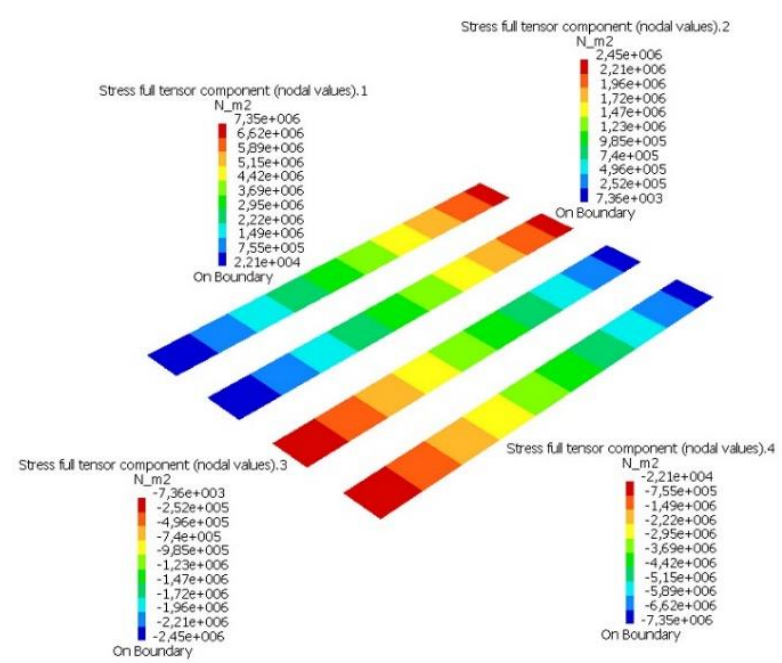

II

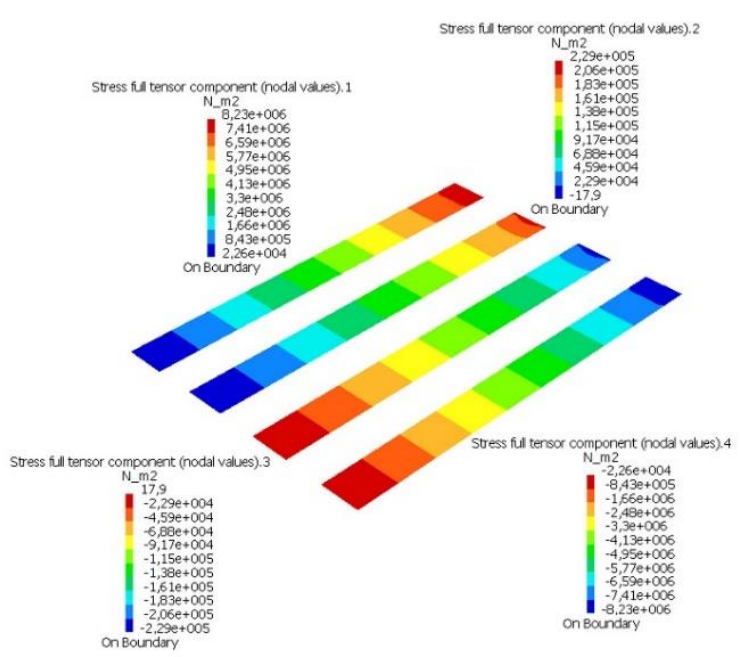

IV 

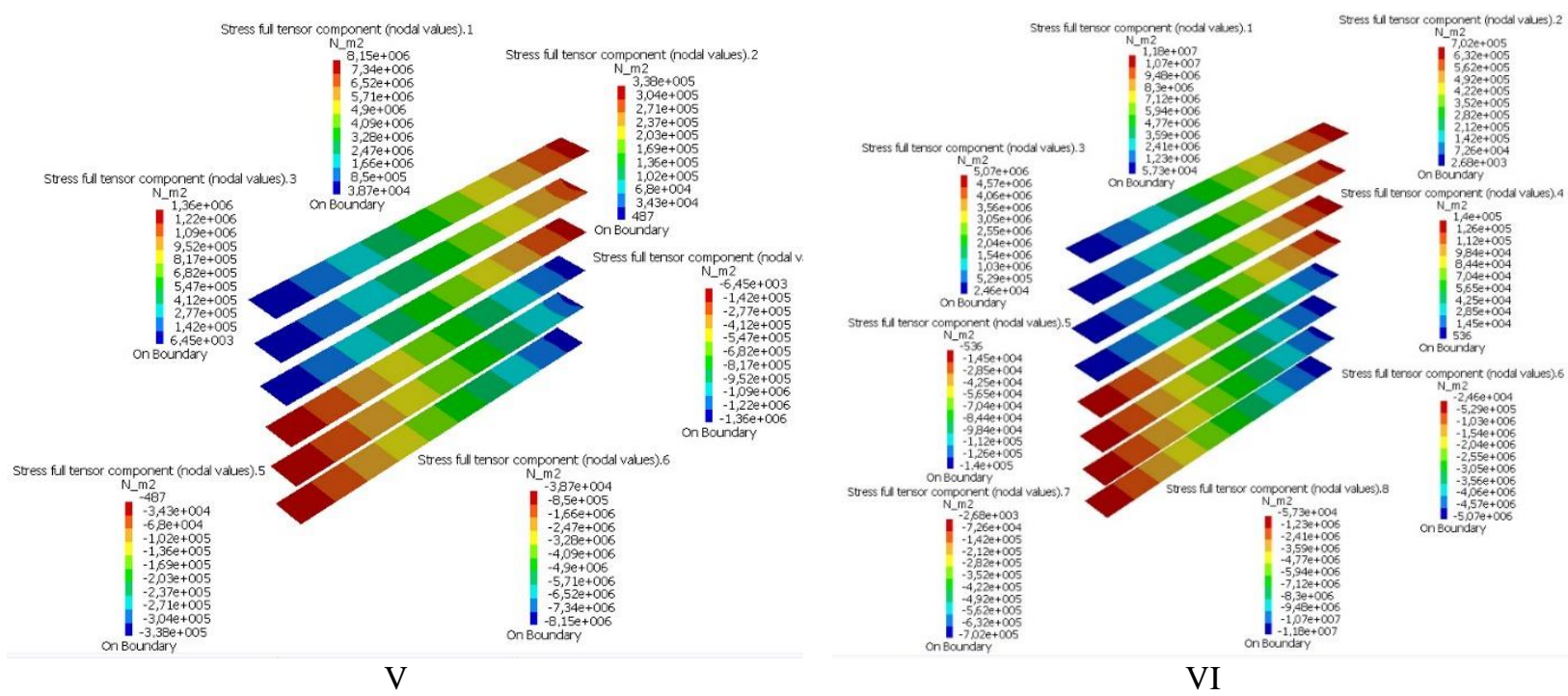

Fig. 6. Stress $\sigma_{z}$ in centroidal plane of the individual layers of the straight cantilever beam

The analytical results of the normal stress of thestraight beam is obtained from:

$$
\sigma_{z}=\frac{M_{x} \cdot y}{I_{x}^{\prime}}\left(\frac{b^{\prime}}{b}\right)
$$

where: $\sigma_{z^{-}}$normal stress, $M_{x}$ - bending moment, $y$ - predetermined distance, $b^{\prime}$ - the transformed width.

Normal stress distribution across the beam cross section $(z=l / 2)$ for six different veneer compositions are shown in Fig. 7. Values and distribution of the normal stress are identical for beams consisting of veneer of the same orientations (case I and II).

Veneers longitudinally orientated (high modulus of elasticity) in span direction are sustain larger stress than veneers with tangential orientation. Normal stress is significantly increased on the surfaces of the beam by reducing the thickness of the external veneers with longitudinal orientation.

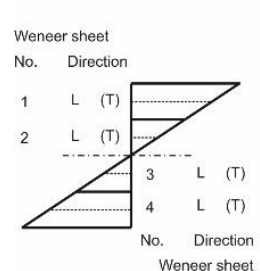

I, II

Component stress $\sigma_{z}, \mathrm{MPa}-$ Cross section at $z=\ell / 2$

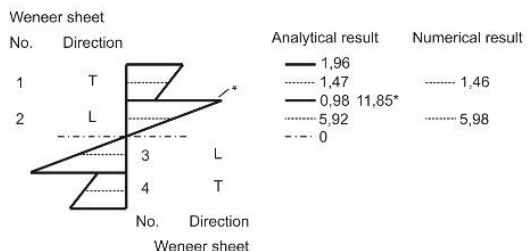

III

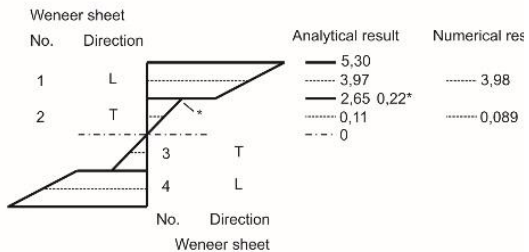

IV
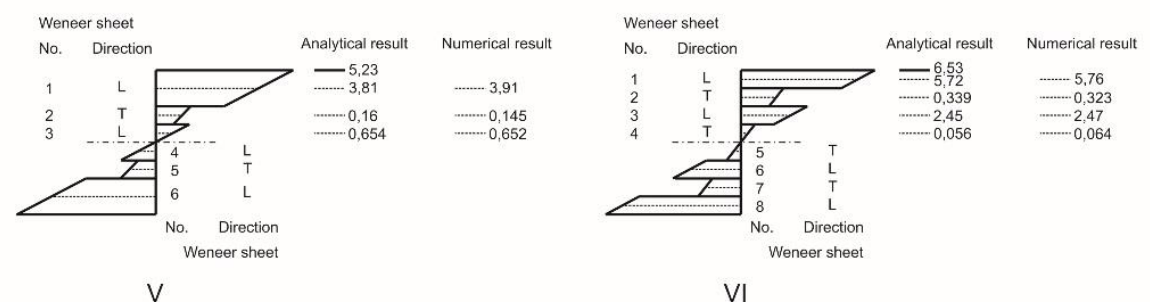

Fig. 7. Analytical and numerical results of the normal stress distribution across the beam cross section for six veneer compositions

The results of the numerical calculation comprising the normal stress $\sigma_{z}$ in the individual layers of the curved cantilever beam are shown in Fig. 8 . 


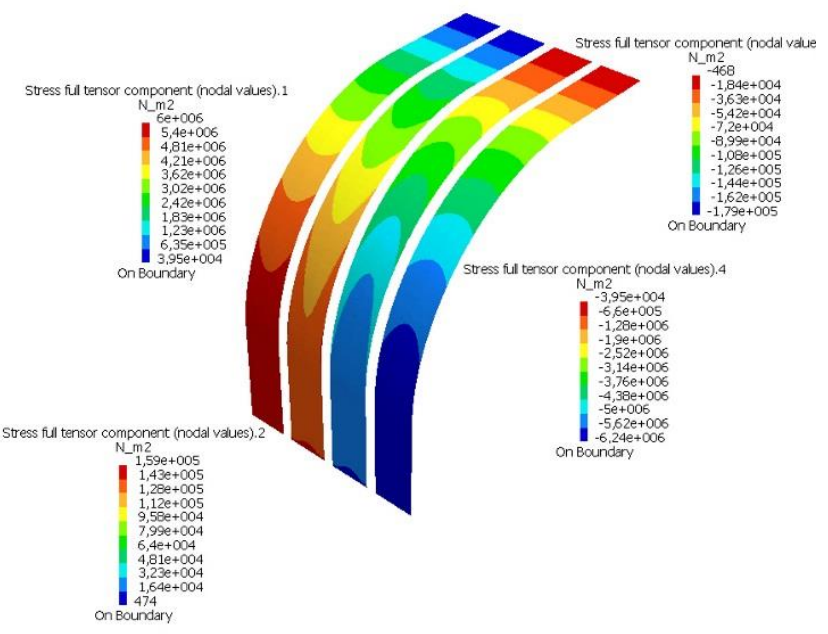

IV

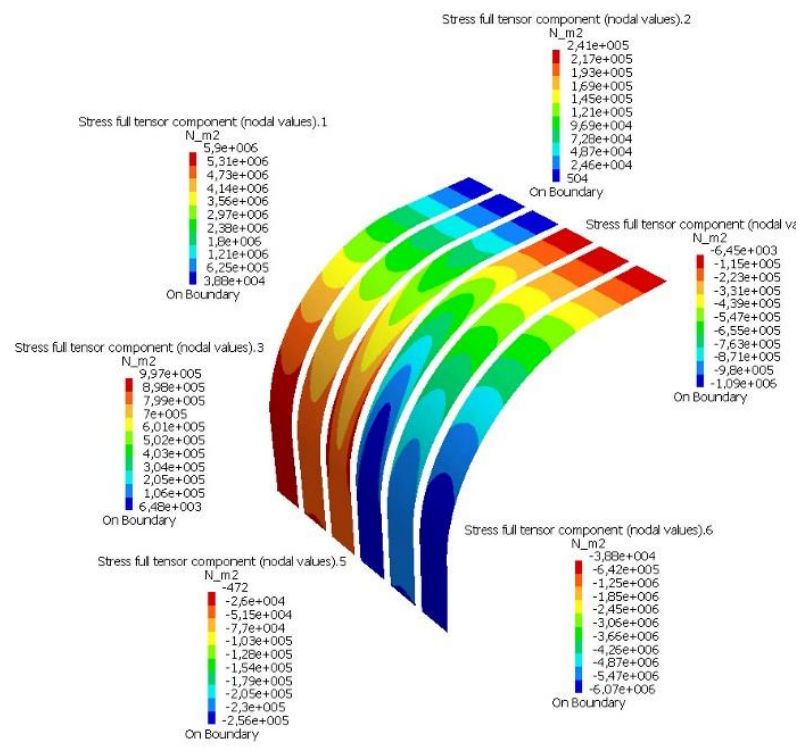

$\mathrm{V}$

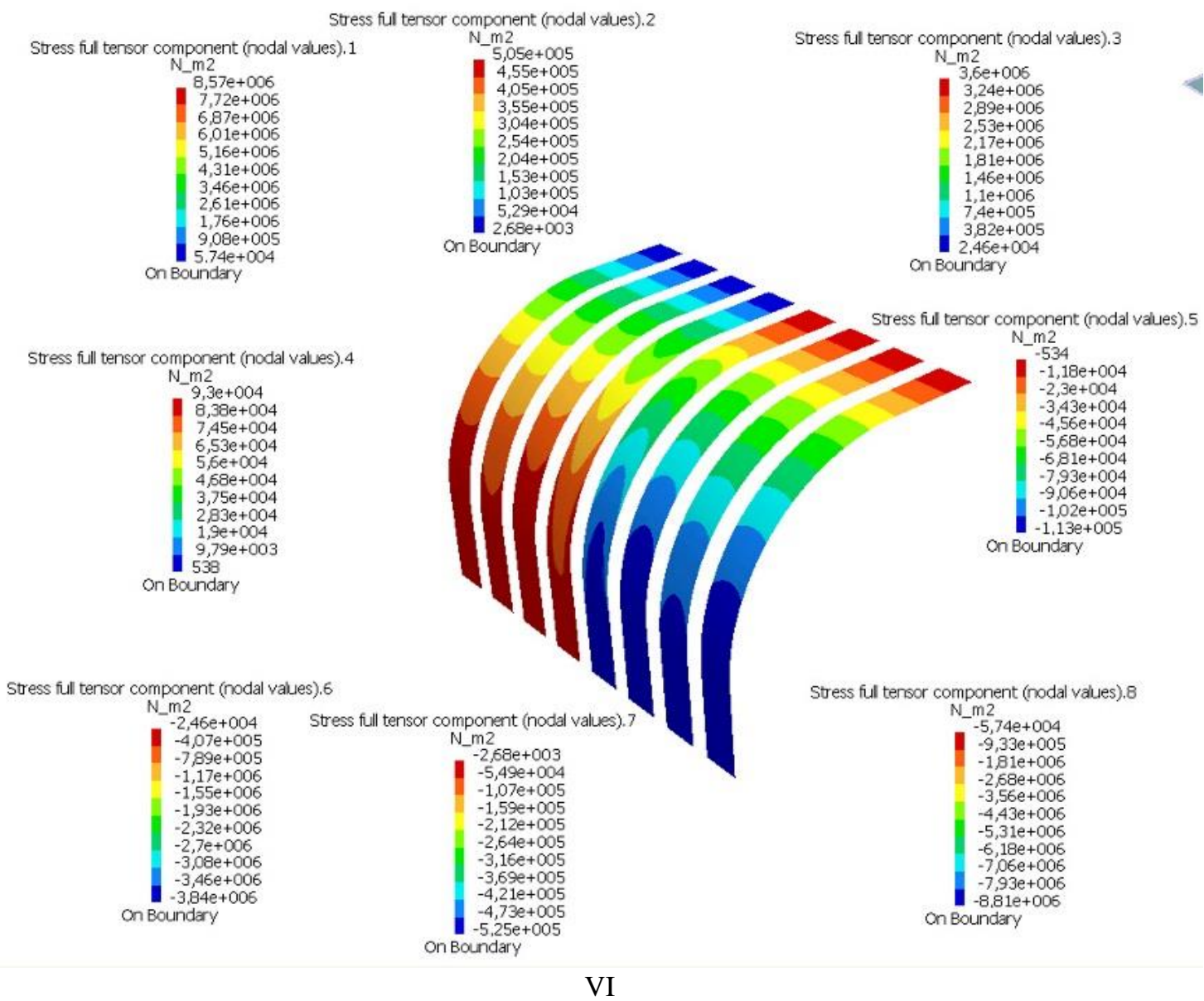

Fig. 8. Stress $\sigma_{z}$ in centroidal curved plane of the individual layers of the curved cantilever beam for three veneer compositions

The neutral axis and the centroidal axis of a curved section of the beam are not coincident and also the stress does not vary linearly from the neutral axis [11]. An approximate estimate of the normal (circumferential) stress in curves section of beam (for $\frac{R}{h}>8$ ) is found as:

$$
e \approx \frac{I}{A r_{c}} \rightarrow \sigma_{\theta}=\frac{M \cdot s}{I} \frac{r_{c}}{r}
$$


where: $r_{c}$ - radius of centroidal axis, $r$ - radius of the elemental fiber from center of curvature, $s$ - the distance from the centroidal axis. The sign convention used is: $M$ is positive if it acts to straighten on the beam curved section and the distance $s$ is positive inwards to the center of curvature.

The computation is based on a transformed section $\left(I_{x}^{\prime}\right)$. Approximate value of the actual normal stress in the curved section of the beam consisting of veneers of diferent properties is found as $\sigma_{z}=\sigma_{\theta}\left(\frac{b^{\prime}}{b}\right)$. The analytical results comprising normal stress for three veneer compositions of the curved section cantilever beam are given in Tab. 3 . The applied bending moment is $M=-F\left(l_{2}+R \sin \theta\right)$ and $\theta=\pi / 2$.

The analytical and numerical results show that the compressive stress at the inner layer (veneer $5,6,7$ and 8 ) is greater that tensile stress at the symmetrical outer layer (veneer 4, 3, 2 and 1).

\begin{tabular}{|c|c|c|c|c|c|c|c|c|}
\hline \multicolumn{3}{|c|}{4 veneer sheets (case IV) } & \multicolumn{3}{|c|}{6 veneer sheets (case V) } & \multicolumn{3}{|c|}{8 veneer sheets (case VI) } \\
\hline $\begin{array}{l}\text { Veneer } \\
\text { number }\end{array}$ & $s, \mathrm{~m}$ & $\sigma_{z}, \mathrm{MPa}$ & $\begin{array}{l}\text { Veneer } \\
\text { number }\end{array}$ & $s, \mathrm{~m}$ & $\sigma_{z}, \mathrm{MPa}$ & $\begin{array}{l}\text { Veneer } \\
\text { number }\end{array}$ & $s, \mathrm{~m}$ & $\sigma_{z}, \mathrm{MPa}$ \\
\hline \multirow{2}{*}{1} & $-0,004$ & 7,647 & \multirow[t]{2}{*}{ 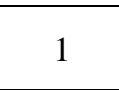 } & $-0,004$ & 7,513 & \multirow{2}{*}{1} & $-0,004$ & 9,431 \\
\hline & $-0,003$ & 5,791 & & $-0,003$ & 5,689 & & $-0,0035$ & 8,292 \\
\hline 2 & $-0,001$ & 0,163 & 2 & $-0,0015$ & 0,240 & 2 & $-0,0025$ & 0,496 \\
\hline 3 & 0,001 & $-0,167$ & 3 & $-0,0005$ & 0,972 & 3 & $-0,0015$ & 3,624 \\
\hline \multirow{6}{*}{4} & 0,003 & $-6,149$ & 4 & 0,0005 & $-0,982$ & 4 & $-0,0005$ & 0,101 \\
\hline & 0,004 & $-8,285$ & 5 & 0,0015 & $-0,247$ & 5 & 0,0005 & $-0,102$ \\
\hline & & & \multirow{2}{*}{6} & 0,003 & $-6,041$ & 6 & 0,0015 & $-3,734$ \\
\hline & & & & 0,004 & $-8,139$ & 7 & 0,0025 & $-0,522$ \\
\hline & & & & & & \multirow[t]{2}{*}{8} & 0,0035 & $-8,894$ \\
\hline & & & & & & & 0,004 & $-10,217$ \\
\hline
\end{tabular}

Table 3. Normal stress for three veneer compositions of the curved section of cantilever beam

\section{Conclusion}

The influence of the veneer composition on the mechanical properties of rectangular and curved form of laminated wood has been investigated by finite element method and transformed cross section method. The possibilities of both used methods for design of different shape of laminated wood has been analysed.

The results show that the veneer fiber orientation, veneer position, and thickness have a considerable impact on the stiffness and normal stress distribution of laminated wood straight and curved beam. It is evident from the analysis that the laminated wood beam is stiffer when the outside veneers have longitudinal orientation in span direction or the thickness of outside veneers with longitudinal orientation is greater. The analysis of stress distribution shows that longitudinally oriented veneers sustain larger stress than veneers with tangential orientation. The normal (circumferential) stress of the inner zone of the curved beam is greater than the normal stress at outer zone.

Similarity between numerical and analytical results of straight beam analysis allows for the conclusion that the research models were designed correctly. The differences between results of curved beam are as a consequence of analytical method that was used, and assumptions and simplifications that were adopted. The results obtained by the transformed cross section method confirm that it can be used to achieve behavior analysis of laminated wood in rectangular form. Curved forms require more complex analysis, but the method can be used to achieve approximate data in early design phase. The research revealed that the numerical procedure used in the study, provides a convenient method of obtaining the information needed for determining basic mechanical properties of laminated wood. The in-plane stress analysis that was applied is not capable to calculating the radial (interlaminar) stresses that are significant factor and the main failure cause in curved forms of laminated wood e.g. laminated veneer products.

In the future investigation the numerical analysis will be extended on the real model of the laminated veneer product. Simulation results will be compared with experimentally obtained results of stiffness and stress.

\section{References}

[1] Boding, J. B.; Jayne, A. (1993). Mechanics of wood and wood composites, Krieger publishing Company, Malabar Florida 
[2] Gonzalez-Cantero, J. M.; Graciani E.; Blazquez, F. \& Paris, F. (2014). Analytic evaluation of radial stress in unfolding failure of composite materials Comparison with numerical solution, ECCM-16th European conference on composite materials, Seville, Spain, 22-26 June 2014

[3] Skovajsa, M.; Sedlacek, F. (2016). Numerical Simulation of Delamination in Laminated Composite Plates Using Cohesive Elements, Proceedings of the 27th DAAAM International Symposium, Vienna, Austria, ISSN 1726-9679, ISBN 978-3-902734-08-2, Katalinic, B. (Ed.), pp. 1726-9679, Published by DAAAM International, DOI: 10.2507/27th.daaam.proceedings.089

[4] Sandberg, D. \& Ormarsson, S. (2007). Numerical simulation of hot-pressed veneer products, working paper no. 2007:19, Vaxjo University, School of Technology \& Design, Sweden

[5] Blomqvist, L.; Johansson, J. \& Sandberg, D. (2013). Basic knowledge of wood properties for improved performance of laminate veneer products, Pro Ligno, Vol.9 No 4 2013, pp. 549-556, ISSN-L 184-4737

[6] Jakimovska Popovska, V.; Iliev, B. \& Zlateski, G. (2017). Impact of veneer Layouts on Plywood Tensile Strength, Drvna industrija, 68 (2) pp. 153-161, doi: 10.5552/drind.2017.1634

[7] Vratuša, S.; Kariž, M.; Ayrilmis, N. \& Kitek Kuzman, M. (2017). Finite element simulations of the loading and deformation of plywood seat shells, Eur. J. Wood Prod. DOI 10.1007/s00107-017-1160-4

[8] Nestorović, B.; Skakić, D. \& Grbac I. (2011). Determining the Characteristics of Composite Structure Laminae by Optical 3D Measurement of Deformation with Numerical Analysis, Drvna industrija, 62 (3) pp. 193-200, doi: 10.5552/drind.2011.1103

[9] Chung, T. J. (1996). Applied continuum mechanics, Cambridge University Press, Cambridge, 1996

[10] Smardzewski, J. (2008). Effect of wood species and glue type on contact stresses in a mortise and tenon joint, Journal of Mechanical Engineering Science, 222(12) 2008, pp. 2293-2299.

[11] Young, W. C. \& Budynas, R. G., (2001). Roark's Formulas for Stress and Strain, McGraw-Hill Professional, ISBN $0-07-072542-\mathrm{X}$ 